\title{
Role of Anti-Müllerian Hormone in the Pathogenesis of Polycystic Ovary Syndrome
}

\author{
Didier Dewailly ${ }^{1 *}$, Anne-Laure Barbotin ${ }^{1,2}$, Agathe Dumont ${ }^{3,4}$, Sophie Catteau-Jonard ${ }^{1,3}$ \\ and Geoffroy Robin ${ }^{3,4,5}$ \\ ${ }^{1}$ Inserm, Laboratory of Development and Plasticity of the Neuroendocrine Brain, Jean-Pierre Aubert Research Centre, Lille, \\ France, ${ }^{2} \mathrm{CHU}$ Lille, Institut de Biologie de la Reproduction-Spermiologie-CECOS, Hôpital Jeanne de Flandre, Lille, France, \\ ${ }^{3}$ CHU Lille, Unité Fonctionnelle de Gynécologie Endocrinienne, Service de Gynécologie Médicale, Orthogénie et Sexologie, \\ Hôpital Jeanne de Flandre, Lille, France, ${ }^{4} \mathrm{CHU}$ Lille, Service d'Assistance Médicale à la Procréation et Préservation de la \\ Fertilité, Hôpital Jeanne de Flandre, Lille, France, ${ }^{5}$ Lille University, EA 4308 "Gametogenesis and Gamete Quality", Lille, \\ France
}

Besides its interest for diagnosis, the finding of an elevated serum AMH level in PCOS has open major pathophysiological issues. This review addresses the three most important issues: 1- the role of $\mathrm{AMH}$ in the disturbed folliculogenesis of PCOS; 2- the role of $\mathrm{AMH}$ in the gonadotropin dysregulation of PCOS and 3 - the role of $\mathrm{AMH}$ in the trans-generational transmission of PCOS. For each of those issues, the clinical and experimental evidences currently available are discussed and pathophysiological hypothesis are proposed.

Keywords: anti-müllerian hormone, polycystic ovary syndrome, androgens, follicle, FSH, anovulation, GnRH, aromatase

\section{INTRODUCTION}

Polycystic ovarian syndrome (PCOS) is the most common endocrine disorder in women of childbearing age and the leading cause of hyperandrogenism (HA) and oligo-anovulation (OA) causing infertility (1). PCOS is characterized by an increased number of ovarian follicles at all growing stages (2-4). This increase is particularly seen in the pre-antral and small antral follicles. Interestingly, it is precisely those follicles that primarily produce $\mathrm{AMH}(5,6)$. Release of $\mathrm{AMH}$ from the granulosa cells (GCs) of antral follicles leads to measurable serum levels, and these concentrations have shown to be proportional to the number of developing follicles in the ovaries. The development of sensitive assays has enabled measuring AMH in serum and its level was found 2-4 fold higher in women with PCOS than in healthy women, as detailed in other articles of this series. This elevated serum AMH level was initially considered a reflection of the increased stock of pre-antral and small antral follicles within polycystic ovaries $(\mathrm{PCO})(7,8)$. In addition, it could also result from an increased production of AMH per follicle (9), due to an intrinsic property of GCs in PCO that will be discussed below.

The elevated serum AMH level in PCOS quickly interested PCOS specialists who saw it as a way of circumventing the heterogeneity of the ultrasound description of polycystic ovarian morphology (PCOM) that is used in the definition of PCOS. Indeed, the antral follicular count (AFC) being very dependent on the material used, some authors investigated the diagnostic value of the serum AMH assay as a surrogate for follicle number per ovary (FNPO) [reviewed in (10)]. Finally, marking the excess of antral follicles in women with polycystic ovary syndrome (PCOS), AMH assay may soon replace and/or complete the ultrasound ovarian morphology criterion in the diagnosis of this syndrome (11). 
Besides its interest for diagnosis, the finding of an elevated serum AMH level in PCOS has open major pathophysiological issues. First, attention has been drawn to its positive association with hyperandrogenism $(\mathrm{HA})(7,8)$, whom mechanisms are discussed in this review. Then, studies have shown correlation with the PCOS phenotypes, as defined by the Rotterdam criteria (phenotype A: amenorrhea or oligomenorrhea $+\mathrm{HA}+$ PCOM; phenotype B: amenorrhea or oligomenorrhea $+\mathrm{HA}$; phenotype C: HA + PCOM; and phenotype D: amenorrhea or oligomenorrhea + PCOM). The highest serum AMH levels are found in phenotype A (12). Conversely, mean AMH serum levels were found to be lower in hyperandrogenic eumenorrheic patients (phenotype C) compared to those with amenorrhea or oligomenorrhea (13), even if they were not hyperandrogenic (phenotype D) (14). This could mean that the AMH excess is the hallmark of a GCs deregulation that plays a major role in the anovulation of PCOS, besides other contributors such as hyperandrogenism and/or excessive $\mathrm{LH}$ secretion and/or hyperinsulinism (15). We will discuss this important issue.

Besides the primary autocrine role of $\mathrm{AMH}$ in the deregulation of GCs of PCO, the recent discovery of the AMH receptor in a significant subset of GnRH neurons suggests possible extragonadal effects of $\mathrm{AMH}$ on the hypothalamicpituitary-gonadal axis (16) that might be exacerbated in PCOS. Finally, recent data suggest that AMH could be involved in the epigenetic re-programming that is now believed to be the main mechanism leading to PCOS at puberty and adulthood (17). The goal of this review is also to discuss this exciting issue.

\section{ROLE OF AMH IN THE DISTURBED FOLLICULOGENESIS OF PCOS}

\section{Is AMH Overexpressed at the Follicle Level?}

The hypothesis of a role for AMH in follicular deregulation of PCOS assumes that the expression of this hormone is exaggerated within each follicle and/or that its signaling pathways are amplified. This is difficult to demonstrate in vivo because the excess of growing ovarian follicles (up to the stage of small antral follicles) in women with PCOS (2) is a confounding factor. Indeed, this alone could explain the rise in $\mathrm{AMH}$ levels because it is those follicles that physiologically secrete AMH (18). In addition, a close correlation has also been shown between plasma $\mathrm{AMH}$ levels and the excess of $2-5 \mathrm{~mm}$ of antral follicles on ultrasound (8). Thus, it is accepted that the increase in granulosa "mass" secondary to the excess of growing follicles explains at least in part the excess plasma AMH level in women with PCOS $(10,19,20)$.

Another explanation, not excluding the first, could be an excess secretion of $\mathrm{AMH}$ intrinsic to the growing follicles of women with PCOS $(9,20,21)$. Some authors have reported a significant increase in the $\mathrm{AMH} / \mathrm{AFC}$ ratio in women with PCOS compared with women with asymptomatic ultrasound PCO and non-PCOS controls $(6,22)$. This suggests a probable over-expression of AMH by the GCs from antral follicles in PCOS women.
In agreement, Pellatt et al. (23) demonstrated in vitro in GCs cultures from oophorectomy specimens that the $\mathrm{AMH}$ concentration in the culture media was 4 times higher in normoovulatory PCOS women and 75 times higher in anovulatory PCOS women compared with GCs from control women. In vivo, Das et al. (24) highlighted that the AMH concentration in follicular fluid of 4 to $8 \mathrm{~mm}$ antral follicles, was 5 times higher, outside of any ovarian stimulation setting. CatteauJonard et al. (25) demonstrated increased transcription of the $\mathrm{AMH}$ gene and its receptor by quantitative RT-PCR on partially luteinized GCs collected during oocyte puncture for in vitro fertilization in women with PCOS, compared with control women. This increased transcriptional activity was seen in both selected intermediate-sized (8-13 $\mathrm{mm}$ mean diameter) and larger dominant follicles (17-22 mm mean diameter). All these data suggest increased expression of AMH by the GCs of women with PCOS, probably secondary to intrinsic dysfunction of these cells.

Nevertheless, all teams do not validate this hypothesis. Owens et al. (26) found no difference in the transcription of the $\mathrm{AMH}$ gene or its receptor in their study which compared the expression of 13 genes by quantitative RT-PCR by GCs from small, unstimulated antral follicles (on ovarian cortex sampled for fertility preservation) and on partially luteinized GCs (in patients benefiting from in vitro fertilization) in women with PCOS vs. control women. On the other hand, Dilaver et al. (27) found no basal increase in the expression of AMH transcripts in cultured GCs from PCO compared with normal ovaries. These results should nevertheless be put into perspective, given the low level of AMH expression in cultured human GCs and the small number of cases studied.

Another explanation at the molecular level could be an increased stability of the messenger RNAs resulting from the transcription of the AMH gene in the GCs of PCOS women. Thus, even if the transcription of the $\mathrm{AMH}$ gene is not increased, an exaggerated stability of the messenger RNAs could lead to a more marked translational activity and thus to an increase in $\mathrm{AMH}$ secretion. The degree of polyadenylation of the $3^{\prime}$ untranslated regions ( $3^{\prime}$-UTR) of mRNAs coding for AMH could be one of the explanations. However, this hypothesis has not been the subject of any specific study to date.

Finally, the role of certain microRNA which are known to be inhibitors of the translation of messenger RNAs, could also be mentioned. Nevertheless, the only study available to date has not been able to confirm this hypothesis.

\section{If It Is Real, What Is the Explanation for the Excess Production of AMH by GCs From PCO?}

At the molecular level, no abnormalities in the AMH gene that could lead to excess transcription have been reported in PCOS women (28). A whole series of studies point to the responsibility of hyperandrogenism, but controversy persists as to the reality of this effect and its mechanisms, which may be direct or indirect.

In vivo data in PCOS patients are contradictory. A possible direct stimulatory effect of androgens on the expression of AMH by GCs was first raised when a positive correlation between 
serum $\mathrm{AMH}$ and androgen concentrations was reported in several series of PCOS women $(7,8,29-31)$. However, many confounding factors may play a role, in particular the positive effect of androgens on the number of growing follicles (32) and thus on the "granulosa mass." Caanen et al. (33) observed that administration of androgens as part of female-to-male transitions induced a significant decrease in AMH levels, but the protocol included the use of a GnRH agonist, which might have confused the results by lowering serum FSH level (see below). Finally, the decrease in serum AMH levels in PCOS patients receiving high-dose cyproterone acetate, a progestin with a potent anti-gonadotropic and peripheral anti-androgenic action, was no greater than under other anti-gonadotropic drugs, such as estrogen-progestin contraceptives $(34,35)$. But here again, serum FSH level is low in these situations.

Similarly, in vitro experimental data are contradictory. An androgen-inhibitory effect of androgens on the secretion of $\mathrm{AMH}$ by Sertoli cells in men has been clearly demonstrated for many years (36). Crisosto et al. (37) demonstrated that highdose testosterone was responsible for decreased levels of $\mathrm{AMH}$ expression in GCs from small bovine follicles. On the contrary, Zhang et al. (38) reported that testosterone caused an increase in AMH mRNA levels in GCs from mouse antral follicles. In women, some authors have not demonstrated any effect of $5 \alpha$ Dyhydrotestosterone (DHT) on the expression of AMH in GCs from control patients, whereas an increase was observed only in GCs from PCOS patients (39). Dilaver et al. (27) also observed this dose-dependent effect of DHT, while that of testosterone was either positive or null according to its concentration in the GCs culture medium. It should be noted that the contradictory results between these different studies on the effects of androgens on the expression of the AMH gene could be explained by the great variability of the models used (different animal species, cell type, analysis method). Moreover, the effect of androgens is to be seen in the complex interactions they have with other important actors at the GCs level, such as FSH and Estradiol (E2), which vary according to the follicular stage and which are not always taken into account in experimental studies (Figure 1) (19).

Several studies suggest an indirect effect of androgens, via an increase in the number of FSH receptors (FSHR) and/or estradiol receptors alpha $(\mathrm{ER} \alpha)$. Many studies converge toward the promoting action of androgens on the transcription and translation of FSHR through genomic and non-genomic effects and this effect is likely enhanced in PCO [reviewed in (19)]. Consequently, the stimulating effect of FSH on AMH expression that occurs in small growing follicles from normal ovaries would be amplified in PCO (40). This can occur as long as follicles do not express aromatase as E2 inhibits AMH expression through its receptor $\operatorname{ER} \beta(41,42)$ (Figure 1).

This last phenomenon might be defective in GCs from PCO. Dilaver et al. (27) reported that excess androgens increase the ratio $\mathrm{ER} \alpha / \mathrm{ER} \beta$, resulting in increased $\mathrm{AMH}$ expression. The importance of the relative expression levels of ER $\alpha$ and ER $\beta$ has been shown earlier (43). Pierre et al. (39) recently reported a significant positive correlation between the ratio of $\operatorname{ER} \alpha / \mathrm{ER} \beta$ transcripts and the concentration of $\mathrm{AMH}$ and an increase in the levels of ER $\alpha$ transcripts in cultured GCs from PCOS women. However, small growing follicles produce very little E2 and this effect of androgens through activation of ER $\alpha$ might not be relevant in vivo. Conversely, at the time of large antral follicle selection for dominance and when activation of $\mathrm{ER} \beta$ is determinant, this effect of androgens maintaining $\mathrm{AMH}$ expression might be part of the mechanisms leading to the follicular arrest of PCOS (see below).

\section{Are the AMH Signaling Pathways Normal in the PCO GCs?}

In addition to increased expression of $\mathrm{AMH}$, the expression of AMH type 2 receptors (AMHR2) is amplified in PCO GCs $(25,39)$. Activation of AMHR2 results in a significant increase in phosphorylation of SMAD 1,5,8 in the mouse (44) and of SMAD 5 in luteinized human GCs (45). Intriguingly, Dilaver et al. (27) recently demonstrated in cultured GCs from PCOs a dose-dependent decrease in phosphorylation of SMAD 1,5,8 (PSMAD 1,5,8) in the presence of $\mathrm{AMH}$, while paradoxically the levels of transcripts of P-SMAD 1,5,8 was increased by about $50 \%$ in controls (but without reaching statistical significance). Obviously, if the implication of a deregulation of the $\mathrm{AMH}$ signaling pathways in PCOS seems to be an interesting issue, other subsequent studies are needed, especially concerning the involvement of inhibitory SMADs.

\section{What Are the Consequences of the Excess AMH on Ovarian Follicles, According to Their Stages?}

\section{Excess AMH Slows Initial Follicular Growth}

This hypothesis is based on the seminal experiment of Durlinger et al. (46). The addition of AMH in cell culture media containing follicles from knockout mice for the AMH gene slowed follicular growth, even in the presence of FSH, suggesting an inhibitory effect of AMH on FSH-dependent proliferation of GCs.

In a situation of high AMH such as PCOS, a slowing of the initial "FSH-sensitive" follicular growth could thus occur and contribute to the accumulation of the number of growing follicles within the ovaries in these patients. However, few data specific to the human species have been found to confirm this pathophysiological hypothesis (3).

\section{Excess AMH Decreases Apoptosis of GCs in Small Follicles}

Some authors have suggested that AMH has an anti-atretic effect on growing follicles during initial follicular recruitment $(27,47)$. Some known pro-apoptotic agents, such as vitamin D and leptin, may act by decreasing the expression of AMHR2 and thus the anti-apoptosis effect of AMH on GCs (47).

The data available in the literature for PCOS women are relatively small. Webber et al. (48) demonstrated in cell culture models a lower apoptosis rate of GCs from pre-antral follicles in women with PCOS compared to controls. By immunocytochemistry, GCs from PCO are less and more frequently stained for the markers of apoptosis and anti-apoptosis than in controls, respectively $(24,49)$. High levels of AMH could be directly involved in this 


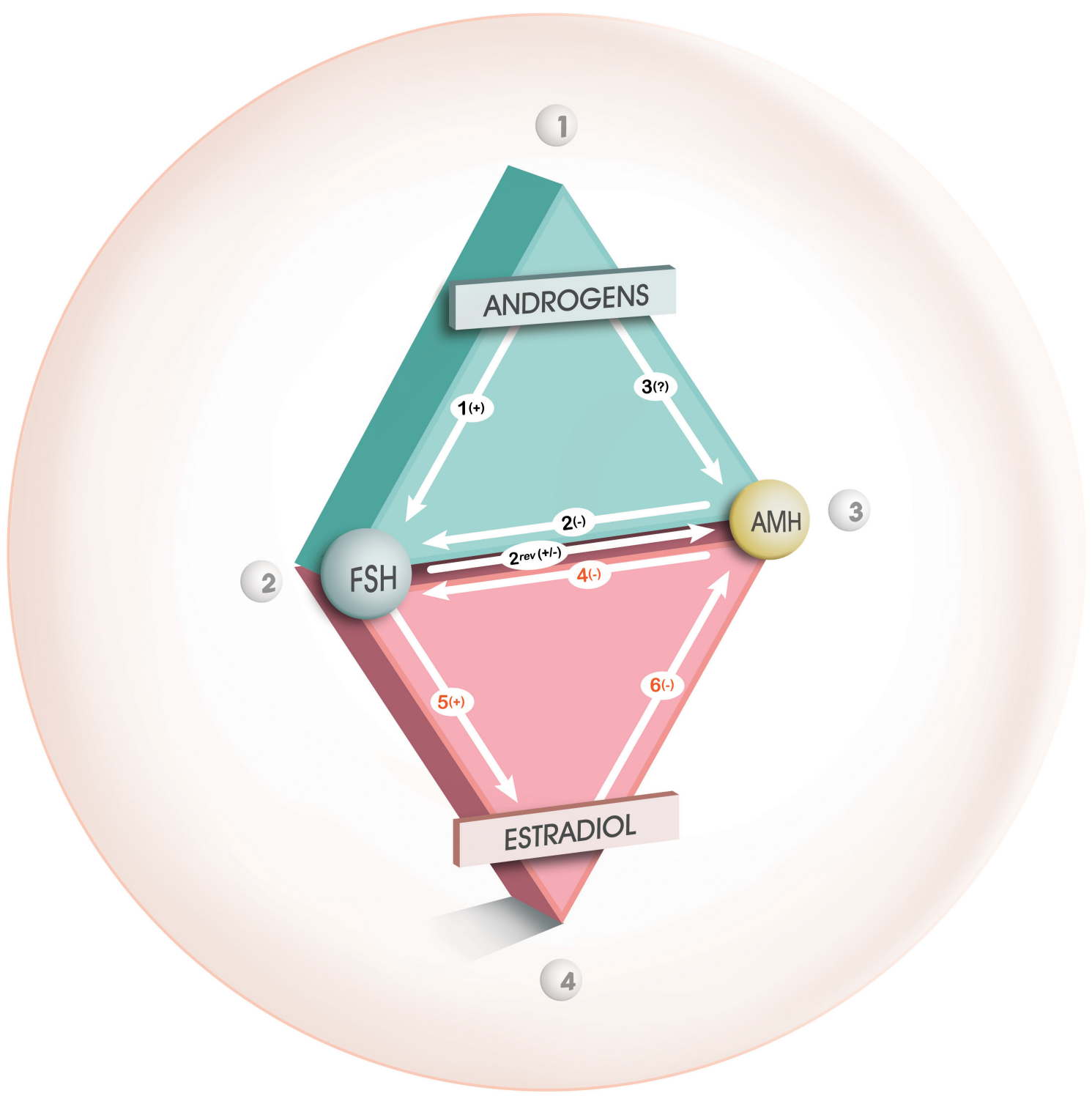

FIGURE 1 | Interaction between androgens, FSH, AMH, and E2 during folliculogenesis. From Dewailly et al. (19), with permission. Relationships between androgens, FSH and AMH during the gonadotropin- independent follicular growth phase (green triangle) and between FSH, AMH and estradiol during the gonadotropindependent follicular growth phase (red triangle). "+," "-," or "?" indicate a positive, negative or uncertain effect, respectively, from one of the factors on the other. During the gonadotropin-independent follicular growth phase, the inhibitory effect of AMH mainly influences the promoting effect of FSH on follicular growth (arrow 2). According to our theory, FSH, whose receptors are enhanced by androgens (arrow 1), would stimulate the AMH production during this phase (arrow 2 rev), in the absence of estradiol. A direct effect from androgens on AMH production (arrow 3) is unlikely (see text for details). During the gonadotropin-dependent follicular growth phase, AMH is also involved in a triangular relationship with FSH and estradiol. During this phase, the inhibitory effect of AMH influences mainly the cell differentiation functions induced by FSH (arrow 4), in particular the induction of aromatase (arrow 5). This inhibitory effect will gradually subside, which will allow induction of aromatase by FSH, with consequent synthesis of estradiol which will in turn accelerates the extinction of AMH secretion in large antral follicles (arrow 6).

phenomenon, which would result in a "stock piling" effect (4) contributing to the excess number of growing follicles in the PCOs.

Finally, as menopause approaches, women with PCOS have significantly higher serum AMH levels than non-PCOS women in whom these levels are low or undetectable (50). This may explain why women with PCOS appear to reach menopause at a slightly later age than non-PCOS women (50).

\section{Excess AMH Causes Follicular Arrest in Large Antral Follicles}

This phenomenon results from complex interaction between $\mathrm{AMH}$, aromatase, ERs and less likely LH (Figure 1).

AMH has been shown to significantly decrease not only FSHR expression but also ovarian aromatase expression [see (19)]. Physiologically, this protects small follicles from premature aromatase expression. When this protective effect of AMH 
exceeds its physiological role, because of its excess and/or because it lasts longer than it should, it could lead to a defect in the selection of the dominant follicle, causing what is called "follicular arrest." The fact that AMH inhibits the FSH-dependent factors necessary for follicle dominance adds considerable importance to the elevated serum expression of $\mathrm{AMH}$ in PCOS and makes AMH an assumed central player in "follicular arrest." In agreement, it has been shown that the emergence of a dominant follicle in anovulatory women with PCOS on recombinant FSH is preceded by a significant reduction in serum AMH level (51).

In addition, several authors have demonstrated premature expression of the LH receptor (LHR) in GCs of PCOS women. This has been suggested to be the cause of the arrest of follicular growth found in PCOS women with anovulation (52, 53). However, this hypothesis seems unlikely because other authors have more recently demonstrated a negative correlation between the concentration of AMH in the follicular fluid and the expression of the LHR in GCs (54).

\section{The AMH Excess in Follicles Varies According to the PCOS Phenotype}

This overexpression of AMH per follicle could vary depending on the PCOS phenotype. Thus, for some authors, in a population of PCOS women, the AMH/AFC ratio was significantly higher in patients with anovulation than in those with an ovulatory phenotype (phenotype $\mathrm{C}$ or asymptomatic ultrasound $\mathrm{PCO}$ ) $(22,55)$. In contrast, other authors have shown higher $\mathrm{AMH}$ levels in hyperandrogenic PCOS women, regardless of ovulatory status $(12,29,31)$. The question of variation in $\mathrm{AMH}$ expression according to the PCOS phenotype is in fact very complex because principal component analysis has shown that the markers of hyperandrogenism and oligoanovulation are closely related (30). However, when both hyperandrogenism and anovulation are statistically confronted with excess serum AMH, the association is significant with the latter, whereas the former would simply be a confounding factor (23).

To summarize, AMH excess in GCs from PCO would be an indirect consequence of hyperandrogenism and would be involved in the follicle excess of PCO and in the follicular arrest in anovulatory patients.

\section{ROLE OF AMH IN THE GONADOTROPIN DYSREGULATION OF PCOS}

A high LH level is found in $\sim 50 \%$ of women with PCOS, with a higher prevalence in women without metabolic impairment (56). It is secondary to the acceleration of the frequency of $\mathrm{GnRH}$ secretion which, for some authors, is thought to be the consequence of a negative feedback failure due to prenatal hypothalamic exposure to androgens (57). Conversely, mean FSH levels are lower than controls in many published series, with no precise explanation provided to date. Both phenomena lead to an increase in the LH/FSH ratio, which was used as a diagnostic criterion in the past, but was abandoned because it was too insensitive. AMH could be involved in this disturbance of gonadotropic function.

\section{There Is a Positive Link Between AMH and $\mathrm{LH}$}

In women with PCOS, serum levels of AMH and $\mathrm{LH}$ are positively correlated (7). This correlation has been shown to be independent of serum androgen and FSH levels (30, 51).

The causal relationship in this relationship has been the subject of debate. For some, the cause would be the high levels of $\mathrm{LH}$ that could stimulate AMH secretion and expression as shown by authors in vitro from luteinized GCs $(23,58)$. However, in vivo, GCs express LHR late, whereas AMH production begins in primary follicles and peaks before LHR expression (5). Alternatively, recent experimental data suggest that $\mathrm{AMH}$ is more likely to have extra-gonadal effects and in particular be capable of increasing the activity of $\mathrm{GnRH}$ neurons. The authors have shown that nearly $50 \%$ of $\mathrm{GnRH}$ neurons (murine and adult human) have specific receptors for AMH type 2 (AMHR2) (16). The combination of several in vitro and in vivo experiments showed that $\mathrm{AMH}$ increased the pulsatile secretion of GnRH-dependent LH through a central action. Indeed, electrophysiological experiments have revealed that exogenous AMH increased the neuronal activity of GnRH neurons; however, this could be an indirect action, as AMHR2 is very widely expressed in the hypothalamic regions, so a synergistic action of other cell types contributing to the increase in GnRH secretion cannot be excluded [for review see (59)]. Similarly, the authors demonstrated that in vivo administration of AMH (intracerebroventricularly) was accompanied by a dosedependent increase in $\mathrm{LH}$ secretion and pulsatility. In the end, the increase in $\mathrm{AMH}$ concentration would lead to a chain reaction: hypothalamic neurons would start to secrete more $\mathrm{GnRH}$, which would then increase the production and pulsatility of LH by the anterior pituitary gland.

$\mathrm{AMH}$ also appears to be able to exert its action at the pituitary level and regulate the activity of gonadotropic cells. It has recently been shown that the expression of the human and mouse AMHR2 gene in gonadotropic cells is regulated by $\mathrm{GnRH}$ (60). Indeed, using L $\beta$ T2 cells, these authors showed that GnRH secreted at a high frequency (1 pulse/30 min) increased AMHR2 expression by gonadotropic cells while a lower frequency (1 pulse/2 h) was without effect. However, the implication of the regulation of pituitary AMHR2 expression as a function of $\mathrm{GnRH}$ pulsatility remains to be elucidated in humans and especially in PCOS.

These results raise the hypothesis that the extra-gonadal action of $\mathrm{AMH}$ could either be at the origin of, or contribute to, the vicious circle of neuroendocrine and gonadal dysregulation encountered in PCOS.

\section{The Negative Link Between AMH and FSH: A Complex Issue}

Low to normal serum FSH levels have long been reported in PCOS (61), even after adjustment for BMI and the number of 2-9 $\mathrm{mm}$ follicles (13). Several studies have reported a negative 
relationship between serum FSH and AMH levels $(8,51)$ but no clear explanation has been provided so far. It is unlikely that this reflects a negative effect of FSH on AMH production. In fact, the opposite is suggested by situations of congenital gonadotropic insufficiency where AMH level is decreased and increases under exogenous FSH (62). These contradictory data illustrate the complex relationships between AMH and FSH that may operate at the ovarian and/or pituitary-hypothalamic levels and which vary according to disease state. In the case of PCOS, we hypothesize that by accelerating the pulse frequency of $\mathrm{GnRH}$ (see above), an excessive AMH level would increase pituitary secretion of LH to the detriment of FSH (63). It is clear that more attention needs be paid to this issue.

To summarize, new experimental data suggests that AMH is involved in the neuro-endocrine deregulation of PCOS but no human data is available so far to confirm this hypothesis.

\section{IS EXCESS AMH INVOLVED IN THE TRANS-GENERATIONAL TRANSMISSION OF PCOS?}

It was in the early 2000s that the hypothesis of prenatal programming of PCOS in relation to gestational hyperandrogenism was first suggested (64). Following this discovery, numerous studies confirmed in various animal models that high testosterone levels during gestation could lead to the appearance of a PCOS phenotype in the offspring (mouse, ewe and non-human primate models) [for review see $(57,65)]$. In women with PCOS, the hypothesis of androgen-related prenatal programming is supported by a whole series of studies [see (17) for review], but the origin of this gestational hyperandrogenism remains unknown so far.

Recent studies suggest that $\mathrm{AMH}$ may be involved in this phenomenon. Circulating AMH levels are higher in pregnant women with PCOS compared to those with normal fertility $(66,67)$ and are correlated with androgen levels $(67)$. These results therefore suggest that $\mathrm{AMH}$ at relatively high concentration during pregnancy could itself be the cause of prenatal programming of PCOS. This has recently been tested experimentally (66). The authors demonstrated that injection of the bioactive form of $\mathrm{AMH}(\mathrm{AMHc})$ into late gestation mice was responsible for the appearance of a hyperandrogenic PCOS phenotype in the offspring in adulthood. In this model, called PAMH, high AMH concentrations during gestation resulted in increased pulsatility of $\mathrm{GnRH}$ and $\mathrm{LH}$, which was responsible for gestational hyperandrogenism. Excess maternal LH alone or in combination with AMH would also lead to a decrease in placental aromatase, increasing maternal bioavailable testosterone and causing fetal exposure to androgen excess. This would induce a cascade of events in the offspring leading to an increase in hypothalamic neuronal excitability. In adult offspring, mice show an increase in excitatory afferents responsible for an increase in the excitability of GnRH neurons. The hyperactivity of GnRH neurons then stimulates ovarian steroidogenesis and participates in the vicious circle observed in PCOS by reducing the negative feedback of E2 and progesterone on LH. Prenatal treatment with a GnRH antagonist in PAMH mice prevents the occurrence of the disorders previously observed in the offspring (66). The authors thus demonstrated the predominant role of GnRH, via $\mathrm{AMH}$, in the in utero programming phenomenon responsible for the neuroendocrine abnormalities characteristic of PCOS appearing in the offspring.

Finally, it should be noted that this new PAMH mouse model suggests that the maternal hyperandrogenisation observed in PCOS is the result of a central action of AMH on GnRH (and $\mathrm{LH}$ ) contributing to an increase in ovarian steroidogenesis and an inhibition of placental aromatase expression, leading to an increase in testosterone bioavailability (66). In agreement, continuous administration of a P450 Aromatase Inhibitor induces Polycystic Ovary Syndrome with a metabolic and endocrine phenotype in female rats at adult age (68). In women, inhibition of placental aromatase expression may be the main mechanism in the in utero programming of PCOS as serum maternal androgen and LH levels are not as high as in PAMH mice. A decrease in placental aromatase has effectively been observed in women with PCOS who have given birth (69). Studies conducted in mice therefore offer interesting new perspectives that will have to be confirmed in the future by clinical studies in women, since the mouse model is poly-ovulatory and is not perfectly superimposable on the human condition.

To summarize, maternal AMH excess might be one of the causes of in utero programming of PCOS, at least in a subset of patients.

\section{CONCLUSION}

There is still much knowledge to be acquired to fully understand the pathophysiological role played by the AMH in the PCOS. Clearly, the autocrine action of excess AMH within the GCs is probably the main element of its involvement in the folliculogenesis and anovulation disorder. However, the recent discovery of its endocrine action of retrocontrol on the hypothalamus and the placenta opens up avenues of research likely to lead to new curative or even preventive treatments. For instance, when they are available, antagonists of the AMHR2 might prove to be able to lessen the $\mathrm{LH}$ and follicle excess and thus to improve the emergence of a dominant follicle and increase the chances of pregnancy without any ovarian stimulation.

\section{AUTHOR CONTRIBUTIONS}

DD contributed to review design, execution, acquisition, analysis and interpretation of data, manuscript drafting, and critical discussion. A-LB, GR, AD, and SC-J contributed to acquisition and interpretation of data, manuscript drafting, and critical discussion. All authors read and approved the final manuscript. 


\section{REFERENCES}

1. Norman RJ, Dewailly D, Legro RS, Hickey TE. Polycystic ovary syndrome. Lancet. (2007) 370:685-97. doi: 10.1016/S0140-6736(07)61345-2

2. Hughesdon PE. Morphology and morphogenesis of the Stein-Leventhal ovary and of so-called "hyperthecosis". Obstet Gynecol Surv. (1982) 37:5977. doi: 10.1097/00006254-198202000-00001

3. Webber LJ, Stubbs S, Stark J, Trew GH, Margara R, Hardy K, et al. Formation and early development of follicles in the polycystic ovary. Lancet. (2003) 362:1017-21. doi: 10.1016/S0140-6736(03)14410-8

4. Maciel GA, Baracat EC, Benda JA, Markham SM, Hensinger K, Chang RJ, et al. Stockpiling of transitional and classic primary follicles in ovaries of women with polycystic ovary syndrome. J Clin Endocrinol Metab. (2004) 89:5321-7. doi: 10.1210/jc.2004-0643

5. Weenen C, Laven JS, Von Bergh AR, Cranfield M, Groome NP, Visser JA, et al. Anti-Mullerian hormone expression pattern in the human ovary: potential implications for initial and cyclic follicle recruitment. Mol Hum Reprod. (2004) 10:77-83. doi: 10.1093/molehr/gah015

6. Bhide P, Dilgil M, Gudi A, Shah A, Akwaa C, Homburg R. Each small antral follicle in ovaries of women with polycystic ovary syndrome produces more antimüllerian hormone than its counterpart in a normal ovary: an observational cross-sectional study. Fertil Steril. (2015) 103:53741. doi: $10.1016 /$ j.fertnstert.2014.10.033

7. Laven JS, Mulders AG, Visser JA, Themmen AP, De Jong FH, Fauser BC. Anti-Mullerian hormone serum concentrations in normoovulatory and anovulatory women of reproductive age. J Clin Endocrinol Metab. (2004) 89:318-23. doi: 10.1210/jc.2003-030932

8. Pigny P, Merlen E, Robert Y, Cortet-Rudelli C, Decanter C, Jonard S, et al. Elevated serum level of anti-mullerian hormone in patients with polycystic ovary syndrome: relationship to the ovarian follicle excess and to the follicular arrest. J Clin Endocrinol Metab. (2003) 88:595762. doi: $10.1210 / j c .2003-030727$

9. Pellatt L, Rice S, Mason HD. Anti-Mullerian hormone and polycystic ovary syndrome: a mountain too high? Reproduction. (2010) 139:82533. doi: 10.1530/REP-09-0415

10. Dewailly D, Andersen CY, Balen A, Broekmans F, Dilaver N, Fanchin R, et al. The physiology and clinical utility of anti-Mullerian hormone in women. Human Reprod Update. (2014) 20:370-85. doi: 10.1093/humupd/d $\mathrm{mt} 062$

11. Fraissinet A, Robin G, Pigny P, Lefebvre T, Catteau-Jonard S, Dewailly D. Use of the serum anti-Müllerian hormone assay as a surrogate for polycystic ovarian morphology: impact on diagnosis and phenotypic classification of polycystic ovary syndrome. Hum Reprod. (2017) 32:171622. doi: 10.1093/humrep/dex239

12. Piouka A, Farmakiotis D, Katsikis I, Macut D, Gerou S, Panidis D. Anti-Mullerian hormone levels reflect severity of PCOS but are negatively influenced by obesity: relationship with increased luteinizing hormone levels. Am J Physiol Endocrinol Metabol. (2009) 296:E23843. doi: 10.1152/ajpendo.90684.2008

13. Catteau-Jonard S, Bancquart J, Poncelet E, Lefebvre-Maunoury C, Robin G, Dewailly D. Polycystic ovaries at ultrasound: normal variant or silent polycystic ovary syndrome? Ultrasound Obstet Gynecol. (2012) 40:2239. doi: 10.1002/uog.11202

14. Sahmay S, Atakul N, Oncul M, Tuten A, Aydogan B, Seyisoglu H. Serum anti-Mullerian hormone levels in the main phenotypes of polycystic ovary syndrome. Eur J Obstet Gynecol Reprod Biol. (2013) 170:15761. doi: 10.1016/j.ejogrb.2013.05.019

15. Franks S, Stark J, Hardy K. Follicle dynamics and anovulation in polycystic ovary syndrome. Hum Reprod Update. (2008) 14:367-78. doi: 10.1093/humupd/dmn015

16. Cimino I, Casoni F, Liu X, Messina A, Parkash J, Jamin SP, et al. Novel role for anti-Müllerian hormone in the regulation of GnRH neuron excitability and hormone secretion. Nat Commun. (2016) 7:10055. doi: 10.1038/ncomms10055

17. Dumesic D, Hoyos LR, Chazenbalk GD, Naik R, Padmanabhan V, Abbott D. Mechanisms of intergenerational transmission of polycystic ovary syndrome. Reproduction. (2019) 159:R1-13. doi: 10.1530/REP19-0197
18. Broekmans FJ, Visser JA, Laven JS, Broer SL, Themmen AP, Fauser BC. Anti-Mullerian hormone and ovarian dysfunction. TEM. (2008) 19:3407. doi: $10.1016 /$ j.tem.2008.08.002

19. Dewailly D, Robin G, Peigne M, Decanter C, Pigny P, Catteau-Jonard S. Interactions between androgens, FSH, anti-Mullerian hormone and estradiol during folliculogenesis in the human normal and polycystic ovary. Hum Reprod Update. (2016) 22:709-24. doi: 10.1093/humupd/dmw027

20. Dumont A, Robin G, Dewailly D. Anti-mullerian hormone in the pathophysiology and diagnosis of polycystic ovarian syndrome. Curr Opin Endocrinol Diabetes Obes. (2018) 25:37784. doi: 10.1097/MED.0000000000000445

21. Bhide P, Homburg R. Anti-mullerian hormone and polycystic ovary syndrome. Best Pract Res Clin Obstet Gynaecol. (2016) 37:38-45. doi: 10.1016/j.bpobgyn.2016.03.004

22. Alebic MS, Stojanovic N, Duhamel A, Dewailly D. The phenotypic diversity in per-follicle anti-Mullerian hormone production in polycystic ovary syndrome. Hum Reprod. (2015) 30:1927-33. doi: 10.1093/humrep/dev131

23. Pellatt L, Hanna L, Brincat M, Galea R, Brain H, Whitehead S, et al. Granulosa cell production of anti-Mullerian hormone is increased in polycystic ovaries. J Clin Endocrinol Metabol. (2007) 92:240-5. doi: 10.1210/jc.2006-1582

24. Das M, Gillott DJ, Saridogan E, Djahanbakhch O. Anti-Mullerian hormone is increased in follicular fluid from unstimulated ovaries in women with polycystic ovary syndrome. Human Reprod. (2008) 23:2122-6. doi: 10.1093/humrep/den185

25. Catteau-Jonard S, Jamin SP, Leclerc A, Gonzales J, Dewailly D, di Clemente N. Anti-Mullerian hormone, its receptor, FSH receptor, and androgen receptor genes are overexpressed by granulosa cells from stimulated follicles in women with polycystic ovary syndrome. J Clin Endocrinol Metabol. (2008) 93:445661. doi: $10.1210 /$ jc.2008-1231

26. Owens LA, Kristensen SG, Lerner A, Christopoulos G, Lavery S, Hanyaloglu AC, et al. Gene expression in granulosa cells from small antral follicles from women with or without polycystic ovaries. J Clin Endocrinol Metabol. (2019) 104:6182-92. doi: 10.1210/jc.2019-00780

27. Dilaver N, Pellatt L, Jameson E, Ogunjimi M, Bano G, Homburg R, et al. The regulation and signalling of anti-Müllerian hormone in human granulosa cells: relevance to polycystic ovary syndrome. Hum Reprod. (2019) 34:246779. doi: 10.1093/humrep/dez214

28. Sproul K, Jones MR, Mathur R, Azziz R, Goodarzi MO. Association study of four key folliculogenesis genes in polycystic ovary syndrome. BJOG. (2010) 117:756-60. doi: 10.1111/j.1471-0528.2010.02527.x

29. Pigny P, Jonard S, Robert Y, Dewailly D. Serum anti-Mullerian hormone as a surrogate for antral follicle count for definition of the polycystic ovary syndrome. J Clin Endocrinol Metabol. (2006) 91:941-5. doi: 10.1210/jc.2005-2076

30. Dewailly D, Pigny P, Soudan B, Catteau-Jonard S, Decanter C, Poncelet E, et al. Reconciling the definitions of polycystic ovary syndrome: the ovarian follicle number and serum anti-Mullerian hormone concentrations aggregate with the markers of hyperandrogenism. J Clin Endocrinol Metab. (2010) 95:4399-405. doi: 10.1210/jc.2010-0334

31. Eldar-Geva T, Margalioth EJ, Gal M, Ben-Chetrit A, Algur N, Zylber-Haran E, et al. Serum anti-Mullerian hormone levels during controlled ovarian hyperstimulation in women with polycystic ovaries with and without hyperandrogenism. Hum Reprod. (2005) 20:1814-9. doi: 10.1093/humrep/deh873

32. Jonard S, Dewailly D. The follicular excess in polycystic ovaries, due to intraovarian hyperandrogenism, may be the main culprit for the follicular arrest. Hum Reprod Update. (2004) 10:107-17. doi: 10.1093/humupd/dmh010

33. Caanen MR, Soleman RS, Kuijper EA, Kreukels BP, De Roo C, Tilleman K, et al. Antimullerian hormone levels decrease in female-to-male transsexuals using testosterone as cross-sex therapy. Fertil Steril. (2015) 103:13405. doi: 10.1016/j.fertnstert.2015.02.003

34. Kallio S, Puurunen J, Ruokonen A, Vaskivuo T, Piltonen T, Tapanainen JS. Antimullerian hormone levels decrease in women using combined contraception independently of administration route. Fertil Steril. (2013) 99:1305-10. doi: 10.1016/j.fertnstert.2012.11.034

35. Plouvier P, Peigne M, Gronier H, Robin G, Catteau-Jonard S, Dewailly D. Is the suppressive effect of cyproterone acetate on serum anti-Mullerianhormone levels in women with polycystic ovary syndrome stronger 
than under oral contraceptive pill? Gynecol Endocrinol. (2016) 18:15. doi: 10.3109/09513590.2016.1145647

36. Rey R, Lukas-Croisier C, Lasala C, Bedecarras P. AMH/MIS: what we know already about the gene, the protein and its regulation. Mol Cell Endocrinol. (2003) 211:21-31. doi: 10.1016/j.mce.2003.09.007

37. Crisosto N, Sir-Petermann T, Greiner M, Maliqueo M, Moreno M, Aedo $\mathrm{P}$, et al. Testosterone-induced downregulation of anti-Mullerian hormone expression in granulosa cells from small bovine follicles. Endocrine. (2009) 36:339-45. doi: 10.1007/s12020-009-9227-6

38. Zhang Y, Wang SF, Zheng JD, Zhao CB, Zhang YN, Liu LL, et al. Effects of testosterone on the expression levels of AMH, VEGF and HIF-1 $\alpha$ in mouse granulosa cells. Exp Ther Med. (2016) 12:883-8. doi: 10.3892/etm.201 6.3436

39. Pierre A, Taieb J, Giton F, Grynberg M, Touleimat S, El Hachem H, et al. Dysregulation of the anti-mullerian hormone system by steroids in women with polycystic ovary syndrome. J Clin Endocrinol Metab. (2017) 102:39708. doi: 10.1210/jc.2017-00308

40. Pierre A, Peigne M, Grynberg M, Arouche N, Taieb J, Hesters L, et al. Loss of LH-induced down-regulation of anti-Mullerian hormone receptor expression may contribute to anovulation in women with polycystic ovary syndrome. Hum Reprod. (2013) 28:762-9. doi: 10.1093/humrep/des460

41. Dumont A, Robin G, Catteau-Jonard S, Dewailly D. Role of antimullerian hormone in pathophysiology, diagnosis and treatment of polycystic ovary syndrome: a review. Reprod Biol Endocrinol. (2015) 13:137. doi: 10.1186/s12958-015-0134-9

42. Grynberg M, Pierre A, Rey R, Leclerc A, Arouche N, Hesters L, et al. Differential regulation of ovarian anti-mullerian hormone (AMH) by estradiol through alpha- and beta-estrogen receptors. J Clin Endocrinol Metabol. (2012) 97:E1649-57. doi: 10.1210/jc.2011-3133

43. Jakimiuk AJ, Weitsman SR, Yen HW, Bogusiewicz M, Magoffin DA. Estrogen receptor alpha and beta expression in theca and granulosa cells from women with polycystic ovary syndrome. J Clin Endocrinol Metab. (2002) 87:55328. doi: $10.1210 /$ jc. $2002-020323$

44. Sèdes L, Leclerc A, Moindjie H, Cate RL, Picard JY, di Clemente N, et al. AntiMüllerian hormone recruits BMPR-IA in immature granulosa cells. PLoS ONE. (2013) 8:e81551. doi: 10.1371/journal.pone.0081551

45. Prapa E, Vasilaki A, Dafopoulos K, Katsiani E, Georgoulias P, Messini CI, et al. Effect of Anti-Müllerian hormone (AMH) and bone morphogenetic protein 15 (BMP-15) on steroidogenesis in primary-cultured human luteinizing granulosa cells through Smad5 signalling. J Assist Reprod Genet. (2015) 32:1079-88. doi: 10.1007/s10815-015-0494-2

46. Durlinger AL, Gruijters MJ, Kramer P, Karels B, Kumar TR, Matzuk $\mathrm{MM}$, et al. Anti-Mullerian hormone attenuates the effects of FSH on follicle development in the mouse ovary. Endocrinology. (2001) 142:48919. doi: 10.1210/endo.142.11.8486

47. Seifer DB, Merhi Z. Is AMH a regulator of follicular atresia? J Assist Reprod Genet. (2014) 31:1403-7. doi: 10.1007/s10815-014-0328-7

48. Webber LJ, Stubbs SA, Stark J, Margara RA, Trew GH, Lavery SA, et al. Prolonged survival in culture of preantral follicles from polycystic ovaries. J Clin Endocrinol Metabol. (2007) 92:1975-8. doi: 10.1210/jc.200 6-1422

49. Das M, Djahanbakhch O, Hacihanefioglu B, Saridogan E, Ikram M, Ghali L, et al. Granulosa cell survival and proliferation are altered in polycystic ovary syndrome. J Clin Endocrinol Metab. (2008) 93:8817. doi: $10.1210 /$ jc. $2007-1650$

50. Piltonen T, Morin-Papunen L, Koivunen R, Perheentupa A, Ruokonen A, Tapanainen JS. Serum anti-Mullerian hormone levels remain high until late reproductive age and decrease during metformin therapy in women with polycystic ovary syndrome. Hum Reprod. (2005) 20:18206. doi: 10.1093/humrep/deh850

51. Catteau-Jonard S, Pigny P, Reyss AC, Decanter C, Poncelet E, Dewailly D. Changes in serum anti-mullerian hormone level during low-dose recombinant follicular-stimulating hormone therapy for anovulation in polycystic ovary syndrome. J Clin Endocrinol Metab. (2007) 92:413843. doi: $10.1210 /$ jc. $2007-0868$

52. Willis DS, Watson H, Mason HD, Galea R, Brincat M, Franks S. Premature response to luteinizing hormone of granulosa cells from anovulatory women with polycystic ovary syndrome: relevance to mechanism of anovulation.
J Clin Endocrinol Metab. (1998) 83:3984-91. doi: 10.1210/jcem.83.1 1.5232

53. Jakimiuk AJ, Weitsman SR, Navab A, Magoffin DA. Luteinizing hormone receptor, steroidogenesis acute regulatory protein, and steroidogenic enzyme messenger ribonucleic acids are overexpressed in thecal and granulosa cells from polycystic ovaries. J Clin Endocrinol Metab. (2001) 86:131823. doi: $10.1210 /$ jc. 86.3 .1318

54. Jeppesen JV, Kristensen SG, Nielsen ME, Humaidan P, Dal Canto M, Fadini $\mathrm{R}$, et al. LH-receptor gene expression in human granulosa and cumulus cells from antral and preovulatory follicles. J Clin Endocrinol Metab. (2012) 97:E1524-31. doi: 10.1210/jc.2012-1427

55. Bhide P, Kulkarni A, Dilgil M, Dhir P, Shah A, Gudi A, et al. Phenotypic variation in anti-Mullerian hormone $(\mathrm{AMH})$ production per follicle in women with polycystic ovary syndrome (PCOS) and isolated polycystic ovarian morphology (PCOM): an observational cross-sectional study. Gynecol Endocrinol. (2017) 33:801-6. doi: 10.1080/09513590.2017.13 20377

56. Huang CC, Tien YJ, Chen MJ, Chen CH, Ho HN, Yang YS. Symptom patterns and phenotypic subgrouping of women with polycystic ovary syndrome: association between endocrine characteristics and metabolic aberrations. Hum Reprod. (2015) 30:937-46. doi: 10.1093/humrep/dev010

57. Walters KA, Gilchrist RB, Ledger WL, Teede HJ, Handelsman DJ, Campbell RE. New perspectives on the pathogenesis of PCOS: neuroendocrine origins. Trends Endocrinol Metab. (2018) 29:841-52. doi: 10.1016/j.tem.2018. 08.005

58. Taieb J, Grynberg M, Pierre A, Arouche N, Massart P, Belville C, et al. FSH and its second messenger cAMP stimulate the transcription of human anti-Mullerian hormone in cultured granulosa cells. Mol Endocrinol. (2011) 25:645-55. doi: 10.1210/me.2010-0297

59. Barbotin AL, Peigné M, Malone SA, Giacobini P. Emerging roles of antimüllerian hormone in hypothalamic-pituitary function. Neuroendocrinology. (2019) 109:218-29. doi: 10.1159/000500689

60. Garrel G, Denoyelle C, L'Hôte D, Picard JY, Teixeira J, Kaiser $\mathrm{UB}$, et al. GnRH transactivates human AMH receptor gene via Egr1 and FOXO1 in gonadotrope cells. Neuroendocrinology. (2019) 108:65-83. doi: 10.1159/000494890

61. Hall JE, Taylor AE, Hayes FJ, Crowley WF. Insights into hypothalamicpituitary dysfunction in polycystic ovary syndrome. J Endocrinol Invest. (1998) 21:602-11. doi: 10.1007/BF03350785

62. Bry-Gauillard H, Larrat-Ledoux F, Levaillant JM, Massin N, Maione L, Beau I, et al. Anti-müllerian hormone and ovarian morphology in women with isolated hypogonadotropic hypogonadism/kallmann syndrome: effects of recombinant human FSH. J Clin Endocrinol Metab. (2017) 102:110211. doi: 10.1210/jc.2016-3799

63. Marshall JC, Griffin ML. The role of changing pulse frequency in the regulation of ovulation. Hum Reprod. (1993) 8(Suppl 2):57-61. doi: 10.1093/humrep/8.suppl_2.57

64. Abbott DH, Dumesic DA, Franks S. Developmental origin of polycystic ovary syndrome - a hypothesis. J Endocrinol. (2002) 174:1-5. doi: 10.1677/joe.0.1740001

65. Stener-Victorin E, Padmanabhan V, Walters KA, Campbell RE, Benrick A, Giacobini P, et al. Animal models to understand the etiology and pathophysiology of polycystic ovary syndrome. Endocr Rev. (2020) 41:53876. doi: 10.1210/endrev/bnaa010

66. Tata B, Mimouni NEH, Barbotin AL, Malone SA, Loyens A, Pigny P, et al. Elevated prenatal anti-Müllerian hormone reprograms the fetus and induces polycystic ovary syndrome in adulthood. Nat Med. (2018) 24:83446. doi: 10.1038/s41591-018-0035-5

67. Piltonen TT, Giacobini P, Edvinsson A, Hustad S, Lager S, MorinPapunen L, et al. Circulating antimüllerian hormone and steroid hormone levels remain high in pregnant women with polycystic ovary syndrome at term. Fertil Steril. (2019) 111:588-96.e1. doi: 10.1016/j.fertnstert.2018. 11.028

68. Maliqueo M, Sun M, Johansson J, Benrick A, Labrie F, Svensson H, et al. Continuous administration of a $\mathrm{P} 450$ aromatase inhibitor induces polycystic ovary syndrome with a metabolic and endocrine phenotype in female rats at adult age. Endocrinology. (2013) 154:434-45. doi: 10.1210/en.201 2-1693 
69. Maliqueo M, Lara HE, Sánchez F, Echiburú B, Crisosto N, SirPetermann T. Placental steroidogenesis in pregnant women with polycystic ovary syndrome. Eur J Obstet Gynecol Reprod Biol. (2013) 166:151-5. doi: 10.1016/j.ejogrb.2012.10.015

Conflict of Interest: The authors declare that the research was conducted in the absence of any commercial or financial relationships that could be construed as a potential conflict of interest.
Copyright (c) 2020 Dewailly, Barbotin, Dumont, Catteau-Jonard and Robin. This is an open-access article distributed under the terms of the Creative Commons Attribution License (CC BY). The use, distribution or reproduction in other forums is permitted, provided the original author(s) and the copyright owner(s) are credited and that the original publication in this journal is cited, in accordance with accepted academic practice. No use, distribution or reproduction is permitted which does not comply with these terms. 